\section{STRENGTH ANALYSIS OF SCREW CONVEYOR DRIVE}

TOMAS CORANIC, JOZEF MASCENIK

Department of Design and Monitoring of Technical Systems, Faculty of Manufacturing Technologies with a seat in Presov, Technical University of Kosice, Presov Slovak

republic

DOI: 10.17973/MMSJ.2021_12_2021185

tomas.coranic@tuke.sk

The present paper deals with research of strength characteristics in manufacturing engineering. The introduction of the work describes findings about the importance of the given subject. The publication is divided into two basic parts, namely the theoretical and the practical part. The theoretical part provides a detailed description of theoretical assumptions on solutions in the field of research, and it also describes optimization of structural units in manufacturing engineering, while the practical part analyses strength characteristics of the selected structural unit which is the drive of a manufacturing machine. The conclusion of the work presents the obtained results.

KEYWORDS

strength characteristics, simulation, impacts in manufacturing engineering

\section{INTRODUCTION}

There are industrial sectors in which a person can encounter manufacturing machines and equipment, and there are impacts occurring during their operation. These impacts have, on one hand, their significance, e.g., work of hammers, mechanical hammers, vibrating conveyors etc.; and on the other hand, there are impacts that occur during operation which are undesired accompanying phenomenon. They increase noise, deterioration and stress of structural units which can result in an incorrect operation of manufacturing engineering components. These are mostly gears, rotors, cam mechanisms and other structural units in which excessive oscillation occurs. Design parameters of the given units should be determined in a way that eliminates an occurrence of sustained motion with an intensive impact. Manufacturing operation influences force effect which results in various changes, e.g., change of velocity, amplitudes, frequencies etc. These changes have a direct impact on reliability of structural units. Calculations are based on theoretical assumptions which are often not the same as operating conditions, such as extremely low or high temperatures, corrosion and others. Therefore, it is necessary to consider not a perfect structural unit with perfect properties. This fact is related to the current tests of structural units which are performed under conditions similar to the operating ones, e.g., under cyclic force, combined loading etc. Time characteristics have a significant effect on strength of structural units[Ivanov 2018, Bun 2019, Husar 2019].

\section{SCREW CONVEYORS}

Screw conveyors are characterised by a simple construction. They are manufactured in various structural forms. This type of conveyors is designed for horizontal and inclined transport. There are bulk, dusty, small and granular materials transported. They are used separately, e.g., for filling truck trunks; or they are integrated into an automated production line. The base of conveyor is use formed by a pipe inside of which there is a working rotating screw. A screw conveyor is on a shaft which is connected to an electric gearbox. Screw conveyors are designed on the basis of specific customers' requirements, according to already specific outputs, requirements for the length criterion of transported material and, of course, according to specifics of the given material [Ruzica 1987, Jasan 1989, Palko 2012]. Material is transported in a screw conveyor by friction against the surface of a screw. Rotational motion performed by a screw in a pipe is designed for a material transport from an input to an output. The gravitational force of which proper operation is conditioned by continuous screw filling is used [Mascenik 2011, Coranic 2021, Majernik 2021]. Screw conveyors are used in various industries, such as automotive, wood processing, pharmaceutical, chemical, nuclear, food, metallurgical, construction, agricultural etc., all shown on Fig. 1.

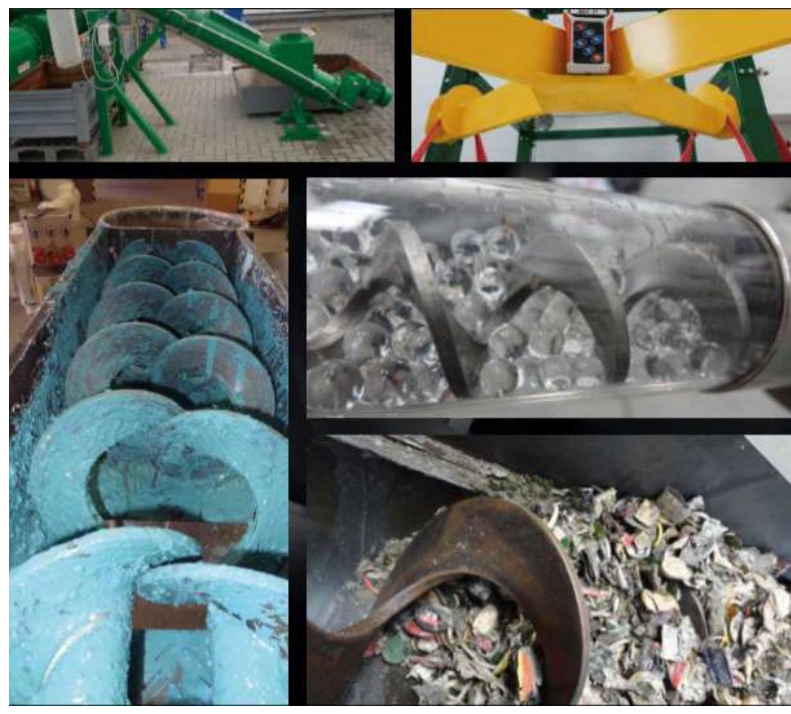

Figure 1. Examples of screw conveyors utilization

\section{STRENGTH CHARACTERISTICS IN MANUFACTURING ENGINEERING}

The first step in constructing reliable structural units is to determine their resistance to disruption. Another aim of the complex process of designing machines and their structural units is to aim for their optimal construction. The resulting solution is often based on contradictory aspects, such as output, used material, manufacturing technology, economic costs, trouble-free operation and operational reliability. The strength characteristics of materials, thus also of structural units, are defined by properties such as hardness, resilience, plasticity, strength, impact strength, fracture strength [Kacalova 2017, Mascenik 2019, Gaspar 2021].

The characteristics of the optimal construction can be summarized into the following several requirements:

- a structural unit must not be disrupted before its designed lifetime,

- $\quad$ all structural units must withstand an operation load on a long-term basis and fulfil their function in such a way that they do not restrict a proper operation of other structural units,

- weight and cost of structural units must be minimal; however, in compliance with their function,

- a possibility of repair and replacement of a component must be ensured [Makarenkov 2012, Mascenik 2014, Mital 2020].

The concept of limit states of structural units includes a whole set of criteria, which are divided into the following two groups: 
1. Group (limit states of bearing capacity):

- static strength,

- plastic state,

- buckling strength and position stability,

- brittle fracture,

- low-cycle and high-cycle fatigue,

- $\quad$ creep during high temperatures.

2. Group (limit states of fitness for use):

- dynamic responses of structural units,

- resistance to impacts and undesirable oscillation,

- $\quad$ allowed static and dynamic transformation.

A limit state of fatigue is a condition in which a disruption of functional capacity component occurs due to exposure to timevarying dynamic characteristics of a load. A typical feature of this event is that the maximum value of the oscillating event is much lower than the static strength of the given element [Pilc 2001, Mascenik 2019, Kascak 2021]. A German engineer, August Wöhler, formulated the following empirical findings which are of general application up to the present day:

- the number of load changes, not the operating time, is important for a fracture of a component that results from a repetitive load,

- material damage is dependent on the difference between the maximum and the minimum stress at the unsafe point,

- $\quad$ the measurement results can be represented in stress coordinates for a number of oscillations (commonly use term nowadays is: "Wöhler's curve"),

- the limit stress after which the fatigue fracture no longer occurs can be determined from the results of experimental measurements.

The main types of material fractures in limit states include:

- fibrous - plastic fracture,

- brittle fracture,

- shear fractures,

- fatigue fractures.

Variable loads which stress structural units during operation often have a complex time course. The cyclic stress that arises in a rotating structural unit can be described according to Fig. 2 . Stress oscillation amplitude can be defined by the pair of values. $\left(\sigma_{\alpha}, \sigma_{\mathrm{m}}\right)$ and $\left(\sigma_{\mathrm{h}}, \sigma_{\mathrm{d}}\right)$.

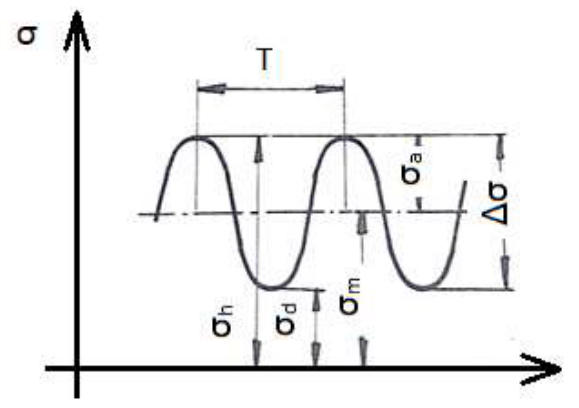

$\mathrm{t}$

Figure 2. Stress oscillation and denomination of quantities

$\sigma_{\mathrm{h}}$ - high-stress amplitude,

$\sigma_{\mathrm{d}}-$ low-stress amplitude,

$\sigma_{\mathrm{m}}-$ medium-stress amplitude,

$\sigma_{\alpha}$ - stress amplitude,

$2 \sigma_{\alpha}=\Delta \sigma-$ oscillation of stresses,

$\mathrm{T}$ - oscillation time,

$f-$ load frequency.
Under the dynamic stress, the material of structural units works under the same divergent conditions as under the static stress. Hence, the strength is lower and after certain cycles an instant fracture occurs. An instant fracture under cyclic stress occurs also under significantly lower stresses than the ultimate strength stress, or slip stress. This event has a complex process of formation. Hence, it can be stated that the strength characteristics of structural units in manufacturing engineering are defined by numerous properties. The main influence is the material composition, its mechanical properties, geometric dimensions of the given unit, the load frequency, the influence of surface treatments, the surface quality and others. Nowadays, structural units are being dimensioned in an increasingly reliable way in manufacturing engineering due to modern technology and new methods of experimental analysis. The best known and most used method is the FEM - Finite Element Method. It is a method that is highly accurate and reliable. The strength and dynamic analyses are solved via the geometry of the analysed structural unit. Creating a network of finite elements via mathematical scientific disciplines is the main idea of the given method [Trebuna 2004, Trebuna 2011, Mascenik 2020].

\subsection{Strength Analysis of Screw Conveyor Drive}

The strength analysis of the defective structural unit of the screw conveyor which is the drive was performed via the Inventor software from the AUTODESK company. The strength analysis is the static analysis of the drive. The 3-D model of the conveyor drive which is shown on the Fig. 3 is a two-stage gear with the SEW SF 67 DRE 100LC4 electric motor type. The first stage consists of the spur gear (gear ratio 2) and the second stage is the worm gear (gear ratio 14). The motor is a threephase asynchronous servomotor with the engine speed of 1455 r.min ${ }^{-1}$.

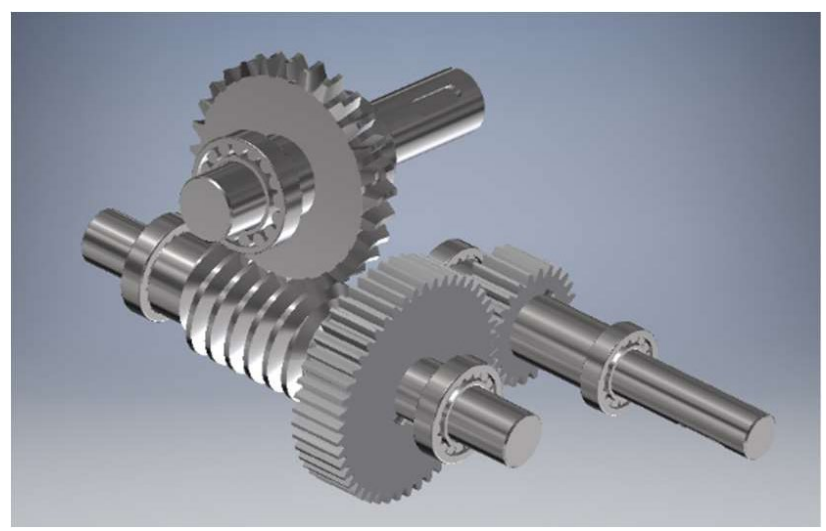

Figure 3. The conveyor gear mechanism 3-D model

The drive was loaded with operating conditions in the software. Based on the parameters of the electric motor with the output of $3 \mathrm{~kW}$ and the speed of $1455 \mathrm{r}$.min-1, the magnitude of the torque.

To perform a strength - static analysis of the drive was possible after entering the geometric, material parameters of the drive and the bonds of individual components. Von Mises stress indicates a dangerous state of the drive occurring when deformation energy during a change of a stress form of structural units exceeds the limit of deformation energy of a form change during linear stress - a failure occurs. The maximum drive stress was calculated to be $57.16 \mathrm{MPa}$. It is important to note that the Von Mises stress (Fig. 4) results are calculated and displayed during the drive strength solution. The 
first principal stress provides information about the stress normal relative to the plane in which the calculated shear stress equals zero. It is used to verify the maximum tensile stress. The third principal stress acts directly in the normal plane which equals zero during shear stress. The third principal stress is used to verify the maximum compressive stress.

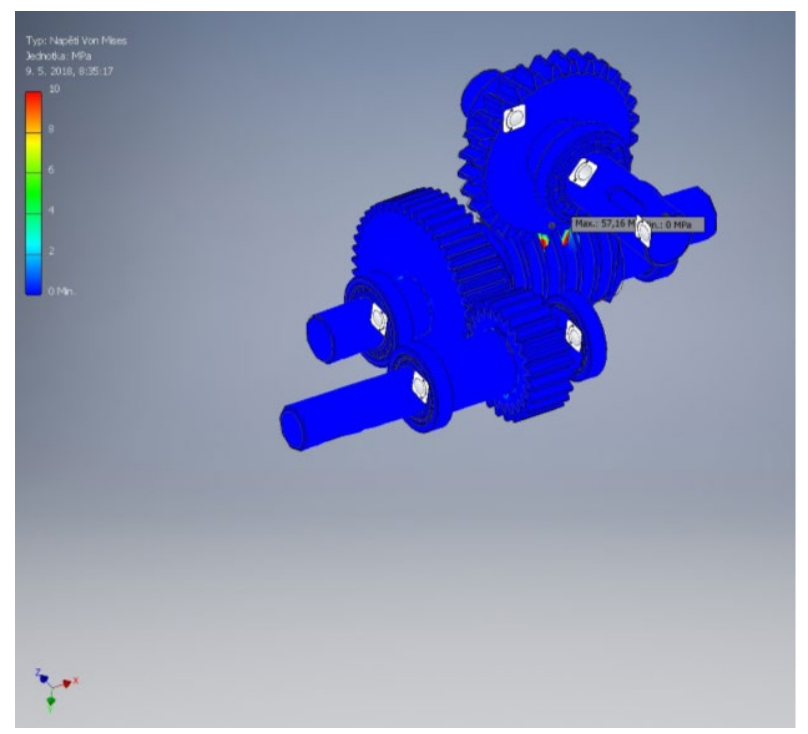

Figure 4. Von Mises drive stress

The resulting values of the drive displacement indicate the deformed shape of the drive model after the solution. The displacement indicates a deformation when compared to the original shape of the drive model. As can be seen from the Fig. 5 , the largest displacements occur at the first stage of the drive which is the spur gear.

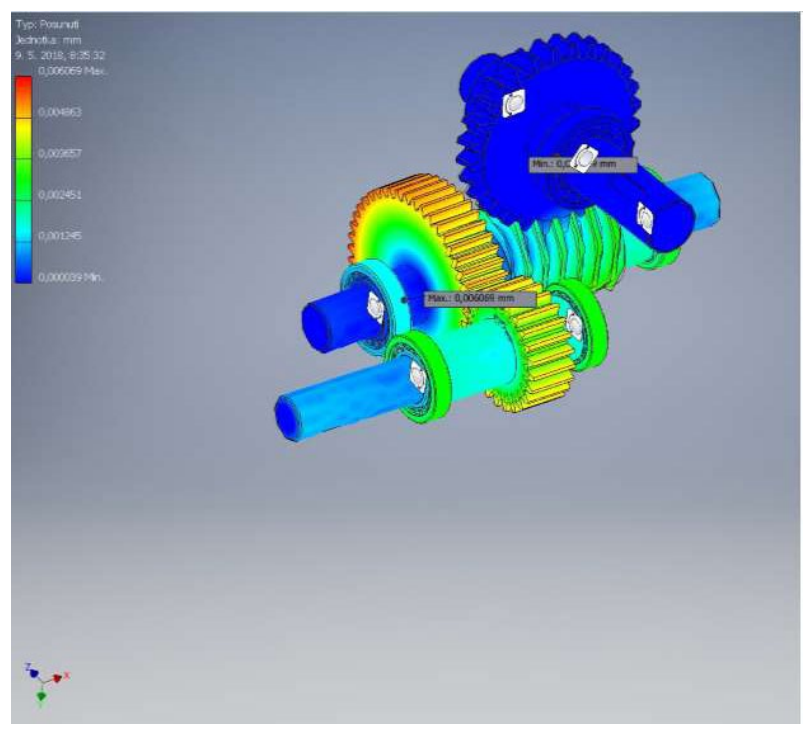

Figure 5. The resulting drive displacement

The drive safety factor indicates the areas of the drive model that the given load will withstand the least with a certain probability. The maximum safety factor was evaluated on the input shaft; while the minimum safety factor was determined on the output shaft of the drive which is the screw (Fig. 6).

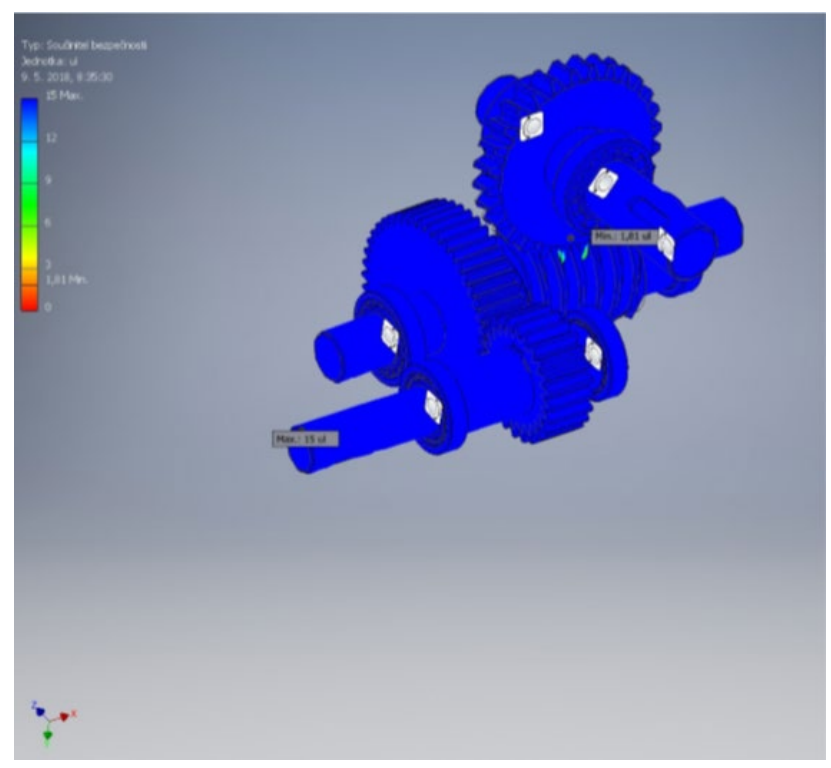

Figure 6. Drive safety factor

\begin{tabular}{|c|c|c|}
\hline $\begin{array}{c}\text { Name of } \\
\text { characteristics }\end{array}$ & Minimum & Maximum \\
\hline Von Mises stress & $\begin{array}{c}0.000000391857 \\
\mathrm{MPa}\end{array}$ & $57.1577 \mathrm{MPa}$ \\
\hline First principal stress & $-5.17168 \mathrm{MPa}$ & $32.3183 \mathrm{MPa}$ \\
\hline Third principal stress & $-58.9294 \mathrm{MPa}$ & $6.01198 \mathrm{MP}$ \\
\hline Stress XX & $-10.5096 \mathrm{MPa}$ & $9.04459 \mathrm{MPa}$ \\
\hline Stress $\mathrm{XY}$ & $-12.7372 \mathrm{MPa}$ & $32.0182 \mathrm{MPa}$ \\
\hline Stress XZ & $-7.43319 \mathrm{MPa}$ & $6.27527 \mathrm{MPa}$ \\
\hline Stress YY & $-51.6339 \mathrm{MPa}$ & $28.9194 \mathrm{MPa}$ \\
\hline Stress YZ & $-8.18473 \mathrm{MPa}$ & $7.0055 \mathrm{MPa}$ \\
\hline Stress ZZ & $-14.7866 \mathrm{MPa}$ & $16.0381 \mathrm{MPa}$ \\
\hline Safety factor & $1.80903 \mathrm{ul}$ & 15 ul \\
\hline Displacement & $0.000039488 \mathrm{~mm}$ & $0.00606947 \mathrm{~mm}$ \\
\hline Displacement X & $-0.000493246 \mathrm{~mm}$ & $\begin{array}{c}0.000420274 \\
\mathrm{~mm}\end{array}$ \\
\hline Displacement $Y$ & $-0.0057757 \mathrm{~mm}$ & $0.00539818 \mathrm{~mm}$ \\
\hline Displacement Z & $-0.00528023 \mathrm{~mm}$ & $0.00601483 \mathrm{~mm}$ \\
\hline
\end{tabular}

Table 1 Values of stresses and displacement occurring in drive

The strength analysis being also the static analysis is the basic step in the subsequent dynamic analysis of the drive. The term analysis can be replaced by the term simulation during which the software evaluated the results of three-dimensional stresses in several directions, i.e. coordinate axes. The threedimensional stress value has a small volume of material and contains normal and shear stresses. Hence, the stress is defined by three normal stresses (stress $X X$, stress $Y Y$, stress $Z Z$ ) and three shear stresses (stress $X X$, stress $Y Y$, stress $Z Z$ ). Tensile normal stresses are positive and compressive normal stresses are negative. Shear stresses are positive in the case that the two axes by which they are defined rotate against each other according to the right-hand rule. The strength analysis shows that the greatest load is in the second drive stage which is the worm gear. The worm gear fulfils an important function and it must be designed accurately, since it is connected to the conveyor screw directly via a carrier. 


\section{CONCLUSIONS}

Certain conclusions can be drawn from the calculated values of the strength and the modal analysis, and from the measured values obtained via the experimental measurements during the drive operation. Via the Autodesk Inventor software in the strength analysis it was concluded that the von Mises stress indicating areas where a deformation and a hazardous condition can occur in the drive is the maximum of $57.15 \mathrm{MPa}$; thus the same stress was marked in the second-stage gear area, i.e. the worm gear. The resulting contact pressure providing information on the pressure on the contact surfaces was evaluated via the software in such a way that the maximum contact pressure occurs in the second gear stage, hence again on the worm gear with the value of $69.47 \mathrm{MPa}$. The safety factor informs about the areas that will with a certain probability withstand the load the least; hence the input shaft of the drive first stage was marked by the factor and its value was 15 , which was also the maximum value of this factor. The minimum safety factor was at the area at the second gear stage, i.e. the worm gear was marked and its value was 1.80 . The security factor is a dimensionless number.

\section{ACKNOWLEDGMENTS}

This article has been prepared within the projects KEGA 017TUKE-4/2021 and VEGA 1/0116/20.

\section{REFERENCES}

[Bun 2019] Bun, P., Trojanowska, J., Rewers, P. VR and AR in Lean Manufacturing Classes. Advances in Manufacturing II, Vol. 1 - Solutions for Industry 4.0. Springer, 2019. ISBN 978-3-030-18714-9.

[Coranic 2021] Coranic, T., Gaspar, S., Pasko, J. Utilization of Optimization of Internal Topology in Manufacturing of Injection Moulds by the DMLS Technology. Applied Sciences, 2021, Vol. 11, 13 p.

[Gaspar 2021] Gaspar, S. et al. Influence of Gating System Parameters of Die-Cast Molds on Properties of Al-Si Castings. Materials, 2021, Vol. 14, 3755

[Husar 2019] Husar, J., Knapcikova, L., Balog, M. Implementation of material flow simulation as a learning tool. Advances in Design, Simulation and Manufacturing. Springer, 2019. https://doi.org/10.1007/978-3-319-93587-4_4

[Ivanov 2018] Ivanov, V. et al. Using the Augmented Reality for Training Engineering Students. Advances in Design, Simulation and Manufacturing, Springer, 2018. ISBN 9781510872226.

[Jasan 1989] Jasan, V., Kosabek, J., Szuttor, N. Theory of transport and handling equipment (Teoria dopravnych a manipulacnych zariadeni). ZU, Zilina, 1989. ISBN 80-05-00125-8. (in Slovak)

[Kacalova 2017] Kacalova, M., Pavlenko, S. Strength and dynamic analysis of a structural node limiting the multi-output gear mechanism, Acta Polytechnica, 2017, Vol. 57, No. 5. ISSN 1210-2709

[Majernik 2021] Majernik, J., Gaspar, S., Husar, J., Pasko, J., Kolinsky, J. Research and Evaluation of the Influence of the Construction of the Gate and the Influence of the Piston Velocity on the Distribution of Gases into the Volume of the Casting. Materials, 2021, Vol. 14, 2264.

[Makarenkov 2012] Makarenkov, O., Jeroen, S., Lamb, W. Dynamics and bifurcations of nonsmooth systems. A survey. Physica D, 2012, Vol. 241, pp. 1826-1844.

[Mascenik 2011] Mascenik, M., Gaspar, S. Experimental Assessment of Roughness Changes in the Cutting Surface and Microhardness Changes of the Material S 355 J2 G3 after Being Cut by Non-Conventional Technologies. Materials Processing Technology, 2011, Vol. 314, pp. 1944-1947. ISSN 1022-6680

[Mascenik 2014] Mascenik, M., Pavlenko, S. Determining the exact value of the shape deviations of the experimental measurements. Applied Mechanics and Materials, 2014, Vol. 624, pp. 229-343.

[Mascenik 2019] Mascenik, J. Implementation of the designed program for calculation and check of chain gears. MM Science Journal, 2019, Vol. Dec, pp. 3431-3434.

[Mascenik 2020] Mascenik, M., Pavlenko, S. Determination of stress and deformation during laser welding of aluminium alloys with the PC support. MM Science Journal, 2020, Vol. Nov., pp. 4104-4107.

[Mital 2020] Mital, G., Spisak E., Mulidran, P., Kascak, L., Jezny, T. 3D evaluation of the topography of the surface by abrasive water jet machining technology. MM Science Journal, 2021, Vol. Oct., pp. 4847-4852.

[Kascak 2021] Kascak, J., Gaspar, S., Pasko, J., Husar, J., Knapcikova, L. Polylactic Acid and Its Cellulose Based Composite as a Significant Tool for the Production of Optimized Models Modified for Additive Manufacturing. Sustainability, 2021, Vol. $13,1256$.

[Palko 2012] Palko, A. Conveyors and conveyor systems (Dopravniky a dopravne systemy). TUKE, Kosice, 2012. ISBN 978-80-7165-871-9. (in Slovak)

[Pilc 2001] Pilc, J., Staneckova, D., Micietova, A. Single-purpose machines and production lines (Jednoucelove stroje a vyrobne linky). ZU, Zilina, 2001. ISBN 80-7100810-9. (in Slovak)

[Ruzicka 1987] Ruzicka, M., Hanke, M., Rost, M. Single-purpose machines and production lines (Dynamicka pevnost a zivotnost). CVUT, Prague, 1987. (in Czech)

[Trebuna 2004] Trebuna, F., Simcak, F. Resistance of elements of mechanical systems (Odolnost prvkov mechanickych sustav). TUKE, Kosice, 2004. ISBN 978-80-807-3148-9. (in Slovak)

[Trebuna 2011] Trebuna, F., Simcak, F. Methods of experimental stress analysis (Metody experimentalnej analyzy napatosti). SJF TUKE, Kosice, 2011. ISBN 978-80-553-0766-4. (in Slovak)

\section{CONTACTS}

M.Sc. Tomas Coranic, PhD.

Department of Design and Monitoring of Technical Systems, Faculty of Manufacturing Technologies with a seat in Presov, Technical University of Kosice, Presov, Slovak Republic

Bayerova 1, Presov, 080 01, Slovak Republic

+421 51772 6315, tomas.coranic@tuke.sk,www.tuke.sk 